Printed

September 11, 1990
RFP-4218

UC-706 ENGINEERING, EQUIPMENT, AND INSTRUMENTS

DOE/OSTI-4500-R75

RFP- -4218

DE91 002534

\title{
MATHEMATICAL MODELLING OF PART VOLTAGE AND WELD CURRENT IN RESISTANCE WELDERS
}

D. E. Destefan

SUBJECT DESCRIPTORS

Data Acquisition System

High Current

Measurement Methods

Resistance Weiding

\author{
EG\&G ROCKY FLATS, INC. \\ ROCKY FLATS PLANT \\ P. O. BOX 464 \\ GOLDEN, COLORADO 80402-0464
}
PREPARED UNDER CONTRACT DE-AC04-90DE62349
FOR THE
ALBUQUERQUE OPERATIONS OFFICE
U.S. DEPARTMENT OF ENERGY




\section{ACKNOWLEDGMENTS}

The author thanks Standards Laboratory personnel who supported this work, directly and indirectly, by use of necessary equipment and calibration aciivities. Special acknowledgment goes to J. Ramboz of the National Institute of Science and Technology, who continues to be a valuable source for discussions and information about high current and pulsed power measurements. The author thanks the reviewers of this paper for their time, helpful comments, and constructive criticisms. Contributions were made by personnel at Sandia National Laboratories, Livermore, Califomia, who supported resistance welding work. The author also thanks $\mathrm{H}$. Bedard, Medar, Inc., who performed initial welder impedance measurements. 


\section{CONTENTS}

$\begin{array}{ll}\text { Abstract } \ldots \ldots \ldots \ldots \ldots \ldots & \end{array}$




\title{
MATHEMATICAL MODELLING OF PART VOLTAGE AND WELD CURRENT IN RESISTANCE WELDERS
}

\author{
D. E. Destefan
}

\begin{abstract}
A mathematical model is presented to describe the part voltage and weld current that occur in a single-phase resistance welder. Developing an accurate model of part voltage and current is the first step toward understanding instrumentation, testing, calibration, and measurement requirements. Mcasurement requirements for dynamic part resistance, calculated from these basic process variables, can ultimately be determincd using this analysis. This model utilizes electrical characteristics of the welder, power system, and parts, as well as geometric parameters of voltagesensing wires to describe the resultant time functions. The complete equivalent circuit involves many resistive and inductive components in the welder primary and secondary circuits.
\end{abstract}

These components are reduced to a simple equivalent circuit to obtain a closed-form solution for part voltage and weld current time functions. Actual measurements were acquired from a welder using a constant resistance load to 1 rify accuracy of the model. Accuracy of the model is estimated to be within the measurement uncertainty and is, in general, approximately $\pm 3 \%$ for current and $\pm 5 \%$ for part voltage. Pertinent limitations of the model's accuracy and range of applications are also discussed briefly.

\section{INTRODUCTION}

State-of-the-art resistance welding systems are being designed and procured for the Rocky Flats Plant (now operated by EG\&G). Specifications, performance testing, and subsequent calibration of these systems require complete understanding of the complex interaction of major process variables in these systems. This understanding is best obtained through a mathematical model describing interaction of the major process variables. Additionally, computerized control and data acquisition systems can be designed with greater confidence in their performance when an accurate mathematical model for process variables is available. The variables of interest in this report are weld current and part voltage.

Heat is required for most welding processes. Resistance welding makes use of Jo..t heating, or $I^{2} R$, heating that occurs when an clectrical current, $I$, passes through a resistance, $R$. The resistance necessary for heat generation in the resistance welding process occurs in the form of contact resistance. This resistance is developed between the surfaces of materials to be welded and results from current constriction effects. ${ }^{1,2}$

When high electrical current passes through the contact resistance, heat is generated at a rapid rate and concentrated at the desired interface. Current levels produced in medium-size resistance welders are in the range of 10,000 A. Typical part resistance values are 100-300 $\mu \Omega$ (micro-ohms). Figure 1 depicts a typical resistance welding system.

The parts to be joined must be maintained in intimate contact, using applied force to maintain an acceptable current path and contact resistance for the weld to occur properly. With the advent of microprocessor weld controllers, weld current and force can be controlled in a very precise manner and have many levels of varying duration and magnitude. All previously mentioned variables have effects on quality of the weld joint as a direct result of heat input variations.

The level and duration of current is achieved by setting two variables in the controller: percent heat and desired number of current cycles. Heat is related to the SCR gating and is discussed in detail later. Cycles are used as a measure of time and are 1/60 


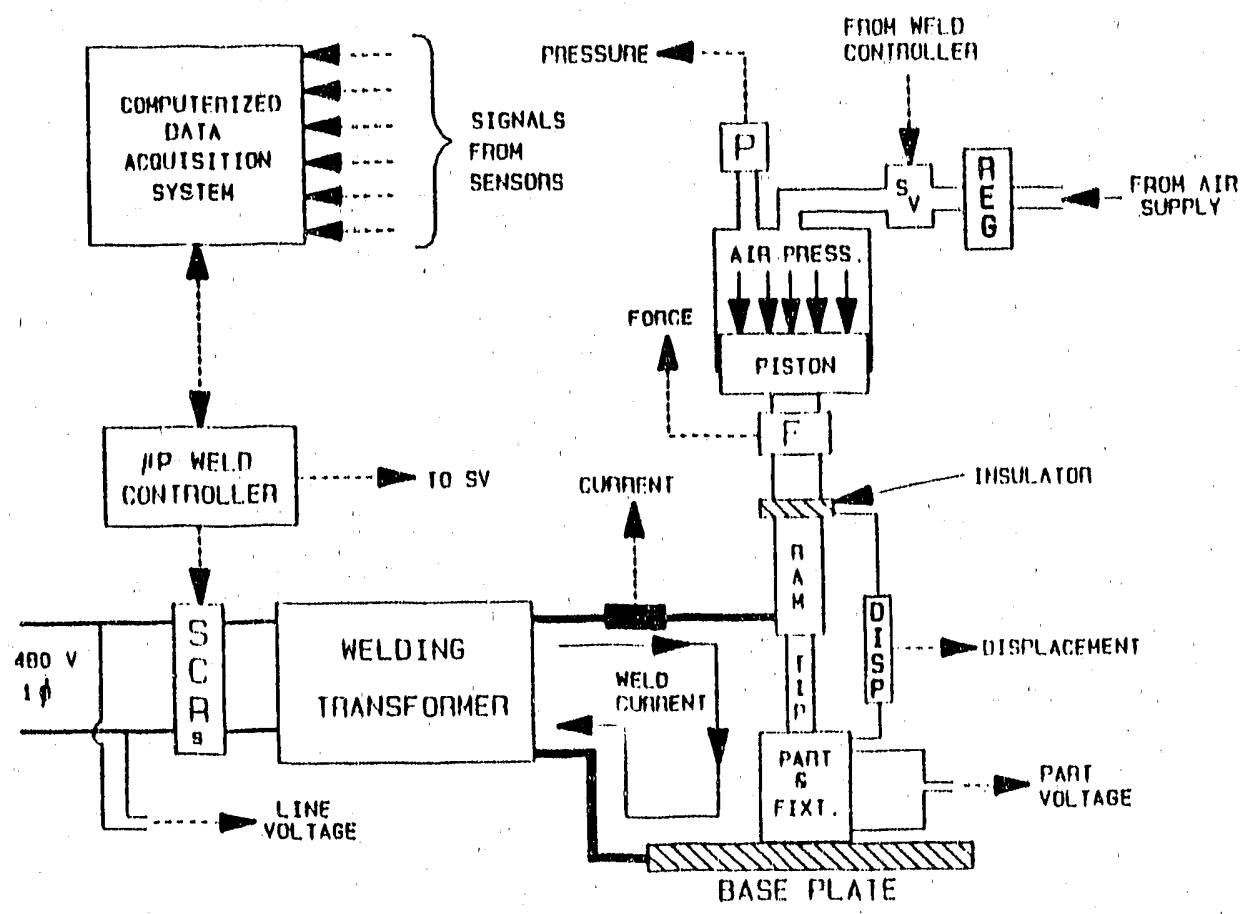

FIGURE 1، Typical Resistance Welding System

second in duration for a power system frequency of $60 \mathrm{~Hz}$. Many of these settings can be programmed in various combinations to provide the necessary sequence of heating and cooling steps for a particular weld.

Power for the welding system is typically provided by a $480-\mathrm{V}$ phase-to-phase connection. Voltage to the welding transformer is controlled by Silicon Controlled Rectifiers (SCR) electronic switches and the weld controller. The welding transformer is a voltage step-down transformer, and its primary-tosecondary turns ratio is about 75 io 1 . When primary voltage is applied to the impedance of the welding circuit, it creates a weld current proportional to the applied voltage and welder impedance.

Typically, parts to be welded are placed in some form of fixturing to maintain mechanical alignment and location of the weld joint. The ram pressure is maintained by a pressure regulator. Application of this pressure to the piston is controlled by an electrically actuated solenoid valve connected to the weld controller. The pressure, whether pneumatic or hydraulic, applies the necessary welding force to the piston, maintaining the parts in intimate contact.
Once the force is applied, the weld controller gates the proper SCR at predetermined times, as determined by the microprocessor weld controller. The term gating implies triggering or firing of the SCR to initiate the conduction mode. The conduction mode allows the SCR to conduct power, initiating voltage to the welding transformer.

Most modern resistance welders have sensors that provide information on such critical variables as weld current, part voltage, part displacement, ram force, and pressure. Part voltage is typically measured by attaching voltage-sensing wires across the weld joint interface as allowed by physical constraints. Based on part voltage and weld current, it is possible to calculate dynamic part resistance, power, and energy. Dynamic part resistance is the joint resistance as a function of weld time.

Information from these sensors is collected by a computerized data acquisition system and can be used for product acceptance, quality control, and welder maintenance. These data can have many formats but, in general, are separated into $60-\mathrm{H} \%$ half-cycle increments corresponding to the smallest control segment possible by the weld controller. 
Because resistance welding has been used in industry for many decades, it might be expected that the process is well understood and described. However, little information is available in the literature to describe intimate details of the equipment and interaction of the process variables. Much of the literature provides only the necessary process equations for the condition of steady-state sinusoidal welding currents. ${ }^{3}$ The steady state, i. e., sinusoidal condition, does not completely describe the process since the welders use phase shift heat control of SCRs. This control method resulis in current pulses that are not sinusoidal in nature. Using high-speed photography, the weld joint temperature has been shown to respund to each half cycle of current. This indicates that the process cannot be accurately described using steady-statc analysis.

Many investigators believe that part resistance is a significant process variablc. Part resistance is a basic parameter in the process because of its relationship to the heat generated at the weld joint. Variations in the part resistance provide a measure of weld quality., 5 Real-time weld control schemes have also been suggested based on dynamic part resistance. Because dynamic part resistance is calculated from the part voltage and weld current waveforms, determination of this parameter includes accurate measurement of both. Precise measurement of resistance is necessary for accurate determination of power and energy in the weld.

Toward the previously stated goals, it was desired to develop a mathematical description of the weld current and the part voltage time functions. The model of the part voltage must include the induced error voltage resulting from close proximity of part voltage-sensing wires to the changing high current.

\section{DERIVATION OF THE MODEL}

\section{Controllers}

It is important to understand the interaction of the weld controller and SCRs before devcloping a mathematical model describing current. This interaction is important to the model since the mathematical description must account for the firing and conduction behavior of the SCRs.
The normal mode of operation for SCRs in resistance welders is natural commutation. In the natural commutation mode, the SCRs are turned on by a weld controller signal and conduct until a reverse current turns off the SCR. This reverse current is supplied, in this particular case, when the weld current attempts to continue conducting past its zero crossing as forced by the applied voltage. Once a firing pulse is sent from the weld controller to the SCR, the controller discontinues control of applied voltage and resulting current until the next half cycle. The length of time that current flows after the SCR firing (current conduction time) is determined by electrical characteristics of the welder.

A weld controller manufacturer may use one of many control algorithms to determine conduction time versus percent heat relationship for gating the SCRs. Understanding the process becomes somewhat complicated unless this is recognized.

Resistance weld controllers use the power system voltage zero crossing as a time reference to gate the SCRs because it is the only true time reference synchronized to the power system. For a given percent heat setting on the weld controller, a predetermined time clapses after the voltage zero crossing when the proper SCR is gated. The elapsed time varies for each controller. In most modem controllers, it is calculated in real time by the controller microprocessor for each half cycle.

Figure 2 provides heat setting ranges for three controllers. The actual current conduction angle as a function of percent heat setting is shown. Current conduction angle is the current pulse duration, measured in angular units. Conduction can also be measured in units (called conduction time). The control algorithm for each controller is indicated in the figurc. Note that for a given percent heat setting a different current conduction angle results for each type of controller. The conduction angle ultimately affects the weld current and (as a direct result) heat produced in the weld.

\section{Equivalent Circuit}

It has been suggested that the resistance welding circuit can be modelled as a sum of resistances and 


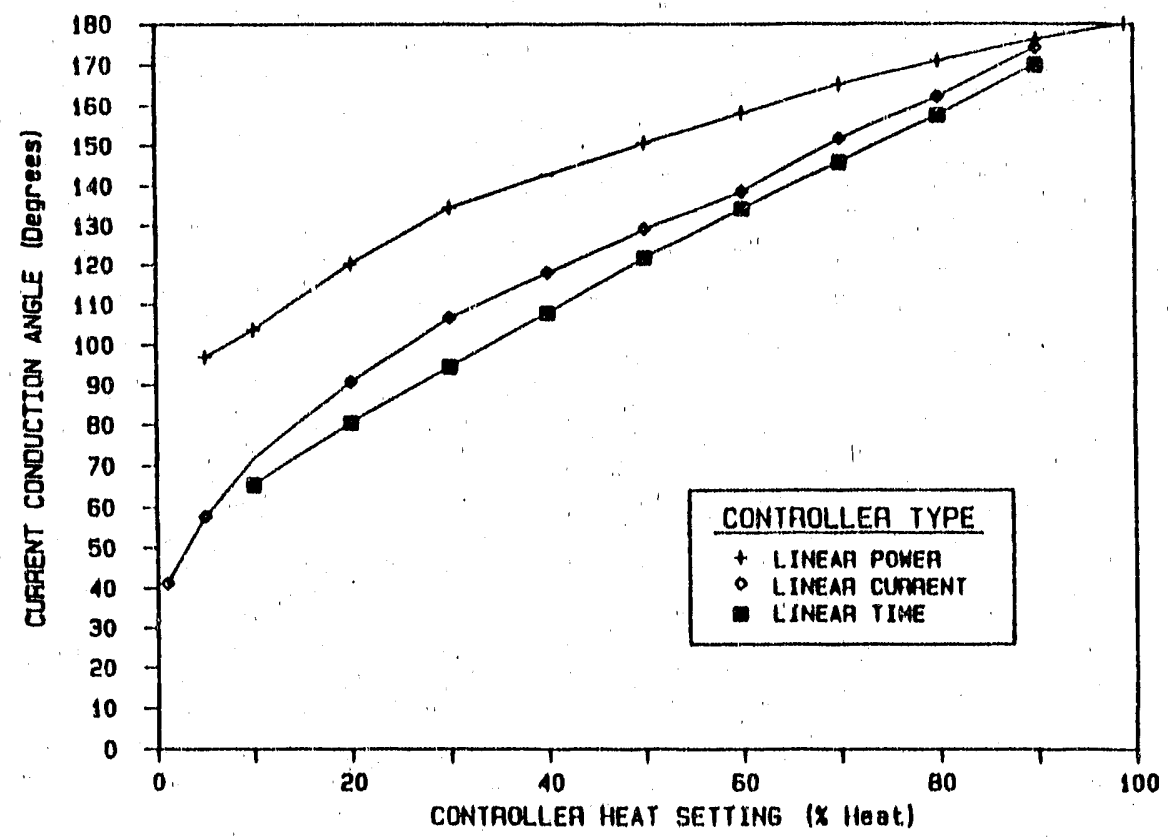

FIGURE 2. Current Conduction Angle as a Function of Controller Heat Setting

inductive reactances. ${ }^{4}$ Resistances occur in both bulk and contact form. It is also suggested that the conductive path has an inductive reactance. Based on these assumptions, a more complete equivalent circuit model for this process can be formulated for a particular resistance welder. It is assumed throughout this discussion that capacitances play an insignificant role in the model. This assumption is consistent with 60$\mathrm{H} z$ system analysis methods. If this assumption is incorrect, the predicted currents and voltages probably will disagree with the measured data significanily.

Starting with the complete equivalent circuit shown in Figure $3 \mathrm{a}$, the source of each resistive or inductive component is described, as well as the reasoning for its existence in the total model. It is assumed that the applied voltage is sinusoidal, having a nominal unloaded value of $480 \mathrm{~V}$. It is standard analysis procedure to assume that a power system impedance can be represented by a series resistance, $R$, and inductance, $L$, component. ${ }^{6}$ This represents the power system short-circuit impedance up to the source of the $480-\mathrm{V}$ power. The feeder providing $480 \mathrm{~V}$ to the welder is likewise represented by Series $R$ and $L .{ }^{7}$

In single-phase resistance welders, SCRs are normally configured in a full-wave connection, thus enabling generation of bipolar current pulses. The welding transformer can be modelled using an ideal transformer turns ratio and a combination of two series RL elements. Each RL pair represents half of the transformer total impedance. This transformer model neglects the magnetizing reactance and core iosses. ${ }^{8}$

Each bus connection in the secondary circuit has a contact resistance at the interface where it meets its adjoining conductor. ${ }^{9}$ Contact resistances are represented as simple resistance elements. Inductance of the contact is neglected because of its relatively small magnitude at low frequencies compared to the contact resistance. ${ }^{10}$

Additionally, each bus or conductor section has a finite bulk resistance and self-inductancc." Each conductor section is a Series RL combination. When connected to provide a complete current-carrying loop, an additional inductive contribution occurs because of the magnetic flux linkage between current-carrying conductors in the secondary circuit. This mutual inductance is shown in Figure $3 a$ as the secondary loop inductance. The remaining resistances in the vertical leg of Figure 3a are contact resistances and bulk resistances of the ram, part, and base plate conductors and interfaces. 


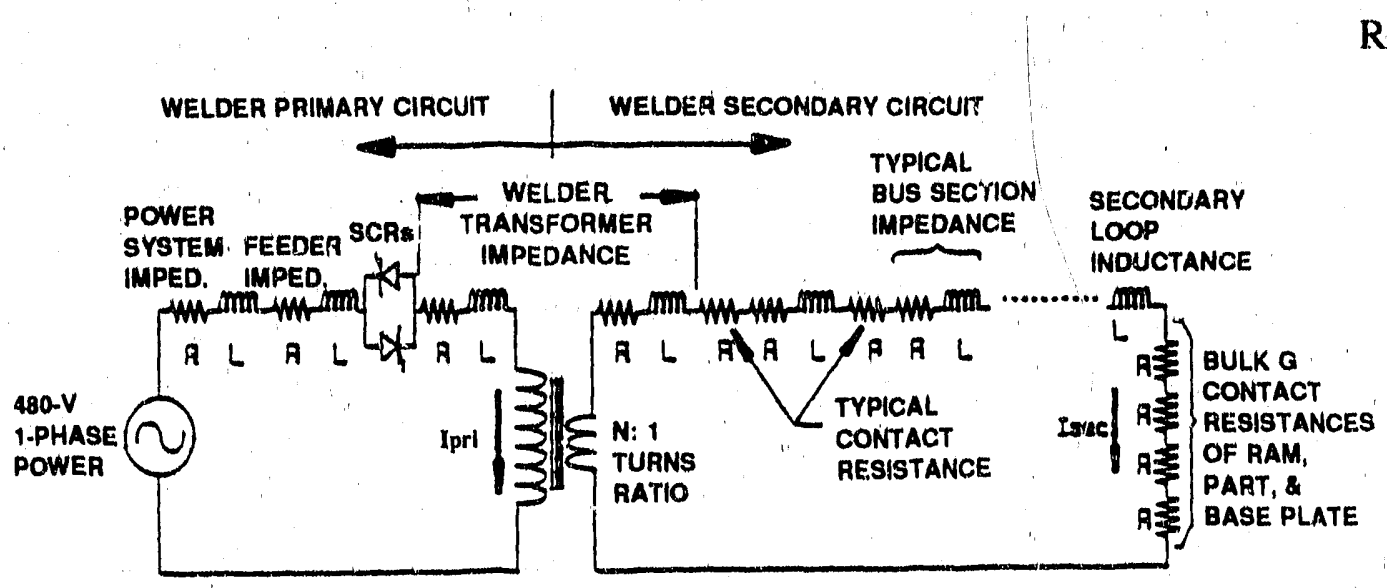

(a) Complete Equivalent Circuit

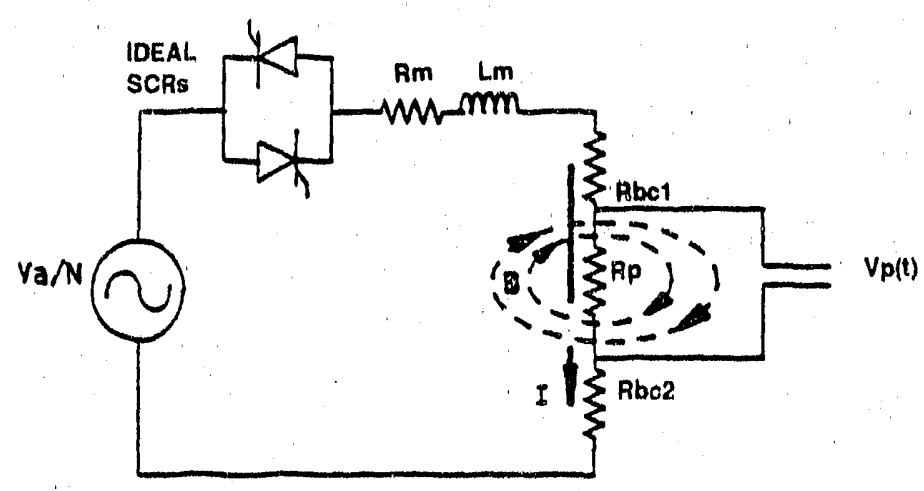

(b) Simplified Equivalent Circult

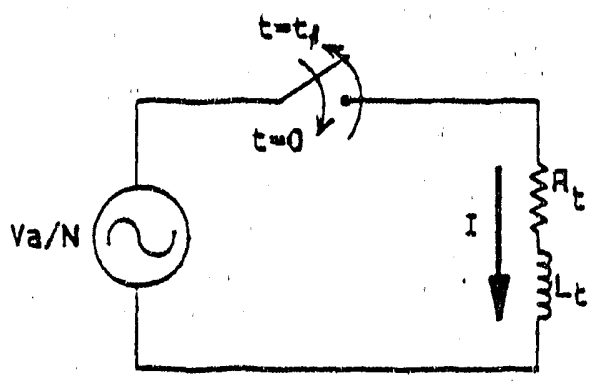

(c) Functionally Equivalent Circuit of (b) for Current Calculation

FIGURE 3. Resistance Welder Equivalent Circuits and Simplifications

Simplifications of the complete equivalent circuit are possible since all components in Figure $3 a$ are connected in series. Once a given machine is installed, many components are fixed for that installation. The feeder impedance, for example, does not change significantly once the cable and conduit are installed.

Simplifications necessary to obtain the circuit shown in Figure $3 \mathrm{~b}$ involve reflecting the primary voltagc source and impedances into the secondary circuit. The primary circuit feeder and power system impedances are cor sted to the secondary circuit equivalent imped' aces by dividing the former by the turns ratio of the transformer squared. The applied voltage (power system nominal voltage) is also reflected into the secondary circuit by dividing by the transformer turns ratio. All secondary impedances shown in Figure $3 \mathrm{a}$ are combined, along with the reflected power system and feeder impedances, resulting in one series RL pair. $R_{m}$ and $L_{m}$ in Figure $3 b$ represent the 
total fixed resistance and total equivalent inductance, respectively, of the welder.

The three remaining resistances in Figure $3 b$ cannot be considered constant. The part resistance, $R_{p}$, represents the actual weld joint contact resistance. The bulk and contact resistances outside of the part resistance are represented by $R_{b c 1}$ and $R_{b c 2}$. These resistances might occur as electrode-to-part or fixturing-to-base plate contact resistances, both of which vary with cleaning, materials, time, pressure, temperature, and part geometry. ${ }^{12.14}$

Actual SCRs display complex turn-on and turn-off character stics. ${ }^{15}$ These, however, can be replaced with an ideal characteristic for purposes of this model. Using ideal SCR characteristics is possible because of the insignificant turn-on and turn-off effects on the total current levels that produce the weld. The turn-on then is characterized as having zero tum-on time once the gate pulse is received from the controller. The turn-off occurs at the instant the current reverses polarity. Along with the above characteristics, it is further assumed that the forward voltage drop of the ideal SCR is negligible, i.e., the SCR has zero resistance when conducting current. Also, it is assumed that the SCR, when not conducting, has infinite resistance.

The circuit of Figure $3 \mathrm{~b}$ is simply a series $\mathrm{RL}$ circuit connected to a sinusoidal voltage source where the SCRs may be tumed on anytime after a voltage zero crossing. Functioning of the ideal SCR is likened to a switrh that closes when the SCR fires. The SCR blocks current conduction in the natural commutation mode at the point of current polarity r $^{\circ}$ versal. This corresponds to the switch opening. A functionally equivalent circuit for determining current is shown in Figure 3c. For simplicity, the model considers only the positive current pulse. This, however, can be extended to any cycle in a piece-wise continuous fashion once the model is complete for a half cycle.

\section{Weld Current}

After recognizing that a resistance welder can be represented as a series RL circuit and that an ideal SCR is simply a switch closing at a predetermined time, the resultant current can be expressed as a mathematical equation. Functionally, the circuit depicted in Figure $3 \mathrm{~b}$ is the same as the one in Figure 3c.

Equation 1 describes voltage drop for the Figure 3c circuit. This derivation is similar to that by J. A. Edminister ${ }^{16}$ with appropriate variable changes to reflect this application. Figure 4 aids understanding of timing and definitions throughout the remainder of this report.

$$
\begin{aligned}
& \frac{\sqrt{2} V_{a}}{N} \sin (\omega t+\phi) \\
& =R, i(t)+L, \frac{d i}{d t} \\
& 0 \leq t \leq t t_{\beta}
\end{aligned}
$$

where $\mathrm{V}_{\mathrm{n}} \quad \begin{aligned} & \text { Magnitude of the applied voltage (volts } \\ & \mathrm{rms})\end{aligned}$

$R_{t}=R_{m}+R_{b c 1}+R_{b c 2}+R_{p}$, the sum of all resistances, bulk and contact ( $\mathbf{R}_{\mathrm{m}}$, $R_{b c 1}, R_{b c 2}$, and $R_{p}$ ) as previously defined

$\mathbf{L}_{1} \quad=$ Sum of all inductances, self and mutual

$\omega=$ Natural frequency of the applied voltage., radians per second

$i(l)=$ Weld current time function

$\frac{\mathrm{di}}{\mathrm{dt}}=$ Current time rate of change

$\mathrm{N} \quad=$ Transformer turns ratio

$\mathrm{t}=$ Time variable relative to firing the SCR

$\phi \quad=$ Angular position of the SCR firing relative to the applied voltage zero crossing

$\mathrm{t}_{\beta} \quad=$ Extinction, or turn-off time, as given by Equation 4 


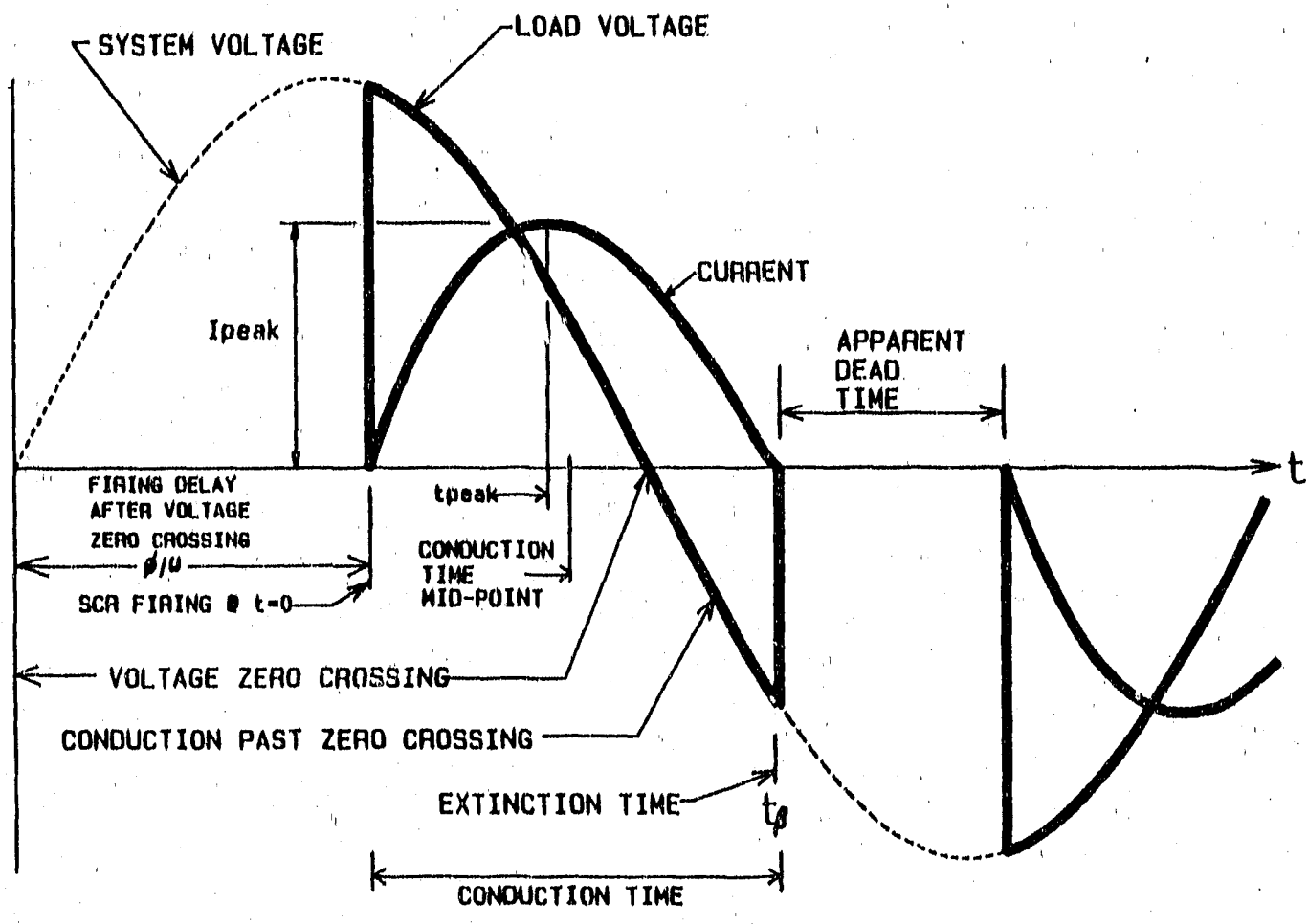

FIGURE 4. Generalized Voltage and Current Waveforms for Equation 2

Solving Equation 1 yields the resultant weld current time function as given in Equation 2 with $t=0$ at the closing of the switch or gating of the appropriate SCR.

$$
\begin{aligned}
i(t) & =K\left(\begin{array}{l}
\sin \left[\omega t+\phi-\tan ^{-1}\left(\omega L_{t} / R_{t}\right)\right] \\
-e^{-\left(R_{t} / L_{t}\right) t} \cdot \sin \left[\phi-\tan ^{-1}\left(\omega L_{t} / R_{t}\right)\right]
\end{array}\right) ; \\
0 & \leq t \leq t_{\beta}
\end{aligned}
$$

(Eq. 2)

where the constant, $\mathrm{K}$, is given by

$$
\mathrm{K}=\sqrt{2} \cdot \mathrm{V}_{\mathrm{a}} /(\mathrm{N} \cdot \mathrm{Z})
$$

and the total impedance magnitude, $Z$, is given by
Equation 2 can be rewritten as:

$$
\begin{aligned}
i(t) & =K\left[\sin (\omega t+\delta)-e^{-t / r} \sin \delta\right] \\
0 & \leq t \leq t_{\beta}
\end{aligned}
$$

where

$$
\delta=\phi-\tan ^{-1}\left(\omega \mathrm{L}_{\mathrm{l}} / \mathbf{R}_{\mathrm{t}}\right)
$$

$$
\tau=\mathbf{L}_{\mathbf{l}} / \mathbf{R}_{\mathrm{t}}
$$

Extinction time, $t_{\beta}$, is defined as the time when the current reverses polarity. This equates to the time an ideal SCR blocks the flow of current. The extinction time can be found by setting Equation 3 equal to zero and solving as:

$$
\sin \left(\omega t_{\beta}+\delta\right)-e^{-t / B} \sin \delta=0
$$

$$
Z_{t}=\sqrt{R_{t}{ }^{2}+\left(\omega \cdot L_{t}\right)^{2}} .
$$


Equation 4 is a transcendental equation, and the solution for the extinction time involves an iterative solution process.

\section{Part Voltage}

The welding community recognizes that part voltage measurement is susceptible to electrical noise created by proximity of the high current. ${ }^{17,18}$ Bieler et al. ${ }^{18}$ quantitatively described the part voltage waveforms from sampled data. Although this method does not provide a closed form solution of part voltage, it does give excellent insight into its nature.

When physical connection of voltage-sensing conductors is made to the weldment, the measured voltage is a combination of the IR voltage drop and an induced error voltage. Physical connection of voltagesensing conductors to a weldment results in a finite separation of the conductors. The high current flowing through this weldment causes a changing magnetic field near these voltage-sensing concluctors.

The total magnetic flux passing through the separation of the voltage-sensing conductors produces induced voltage on these conductors. The induced voltage is proportional to the product of the magnetic flux rate of change and the area formed at the wire separation. This condition is portrayed in Figure $3 b$. Therefore, in addition to the desired part voltage created by the weld current flowing through the part resistance, an error voltage is created by the changing magnetic field surrounding the part resistance.

Voltage induced in a circuit caused by a time varying magnetic field can be expressed by: 19

$$
V(t)=-\frac{d \psi}{d t}
$$

where

$$
\begin{aligned}
\psi= & \begin{array}{l}
\text { Total magnetic flux crossing the signal } \\
\text { wires }
\end{array} \\
V(t)= & \begin{array}{l}
\text { Induced voltage time function resulting } \\
\text { from the changing magnetic ficld }
\end{array}
\end{aligned}
$$

The total magnetic flux, $\psi$, is given by:

$$
\Psi=\int_{\mathbf{S}} \mathbf{B} \cdot \mathrm{d} \mathbf{S}
$$

(Eq. 6)

where

$$
\begin{aligned}
\mathbf{S}= & \text { Surface area of the sense wires } \\
\mathbf{B}= & \begin{array}{l}
\text { Magnetic flux density intercepting the } \\
\text { surface area }
\end{array} \\
\mathrm{dS}= & \begin{array}{l}
\text { Differential suiface area of the voltage- } \\
\text { sensing wires }
\end{array}
\end{aligned}
$$

Most practical part and fixturing geometries contain irregular shapes and current paths. Without extensive analysis of such geometries and current distributions, the magnetic flux density function cannot be determined. Furthermore, even with extensive analysis, a closed form of the magnetic flux density would not result. The particular parts and fixturing of interest have only one current path from the ram tip to the base plate. Therefore, this was approximated with a single conductor extending between those points.

The magnetic flux density was approximated using the ideal geometry of a round isolated infinitely long conductor. The magnetic flux density for this condition is expressed as:

$$
\begin{aligned}
& \mathbf{B}=\frac{\mu O I}{2 \pi r} \mathbf{a}_{\phi} ; \\
& r \geq r_{c}
\end{aligned}
$$

where

$$
\begin{aligned}
& I=\text { Instantancous current } \\
& \mathbf{B}=\text { Magnetic flux density } \\
& \mu_{0}=\begin{array}{l}
\text { Permeability of free space }=4 \pi \times 10^{-7} \\
\text { henrics/meter }
\end{array} \\
& r=\begin{array}{l}
\text { Radial distance from the axial center line } \\
\text { of the current carrying conductor }
\end{array}
\end{aligned}
$$


$r_{c}=$ Radius of the current carrying conductor

$\mathbf{a}_{4}=$ Unit vector indicating $\mathbf{B}$ is tangential to radial direction

The induced voltage on the signal wires measuring part voltage can be related to the mutual inductance of the signal wire loop area. The induced voltage, $V(t)$, can be determined from Equation 8. The equivalent loop area inductance can be found in Equations 5 through 8 for the above ideal geometry.

$$
V(t)=-L \frac{d i}{d t}
$$

\section{(Eq. 8)}

The loop area inductance is described by Equation 9 for the case of a rectangular area formed by the signal wires and a cylindrical conductor of infinite extent.

$$
L_{L}=\frac{H \mu O}{2 \pi} \ln \left[\left(r_{c}+w\right) / r_{c}\right]
$$

\section{(Eq. 9)}

where

$$
\begin{aligned}
& \mathrm{L}_{\mathrm{L}}=\begin{array}{l}
\text { Equivalent mutual inductance of the loop } \\
\text { area formed by the voltage-sensing wires }
\end{array} \\
& \mathrm{H}=\text { Height of the loop area } \\
& \mathrm{W}=\begin{array}{l}
\text { Width of the loop area in the radial } \\
\text { direction }
\end{array} \\
& \mathrm{r}_{\mathrm{c}}=\text { Radius of the current carrying conductor }
\end{aligned}
$$

Using superposition, the sensed voltage is the sum of an in-phase component of the product of current and part resistance plus the product of the loop area inductance and the current time rate of change:

$$
V_{p}(t)=R_{p} i(t)+L_{L} \frac{d i}{d t}
$$

(Eq. 10) where

$$
\begin{aligned}
& \mathrm{V}_{\mathrm{p}}(\mathrm{t})=\begin{array}{l}
\text { Time function of the actual part } \\
\text { voltage sensed }
\end{array} \\
& \mathrm{R}_{\mathrm{p}} \quad=\text { True part resistance } \\
& \mathrm{L}_{\mathrm{l}} \quad=\text { Equivalent loop area inductance }
\end{aligned}
$$

Differentiating Equation 2 to obtain $\mathrm{di} / \mathrm{dt}$ and substituting Equation 2 for $\mathrm{i}(\mathrm{t})$ into Equation 10 yields the total part voltage. Total part voltage contains both the resistive voltage drop and induced error voltage components. The voltage appearing at the conductors when attached to a part resistance is given by:

$$
\begin{aligned}
V_{p}(t) & =K\left(\begin{array}{l}
R_{p}\left[\sin (\omega t+\delta)-e^{-t / \tau} \sin \delta\right] \\
+L_{L}\left[\omega \cos (\omega t+\delta)+\frac{1}{\tau} e^{-t / \tau} \sin \delta\right]
\end{array}\right) \\
0 & \leq t \leq t_{\beta}
\end{aligned}
$$

\section{EXPERIMENTAL PROCEDURE}

No mathematical model is particularly useful unless its accuracy or ability to describe a particular event is known. It was necessary to devise a means for determining accuracy of the above equations to describe the weld current and part voltage time functions. When developing an experimental verification of a model, it is important to avoid introducing additional variables that are not easily controlled or verified. These concerns preclude using an actual weldment since its resistance changes during current flow. ${ }^{20}$

As stated previously, an actual weld joint can be represented as a contact resistance without significant inductance. The experimental load simulating part resistance must possess the same characteristic. For purposes of the experiment, the load must not have significant change in resistance with current flow because this would introduce an additional variable in 
the equations--namely, a rate of change in part resistance.

The above differential equations are classified as linear-constant coefficients. This means that if these equations are to describe current and part voitage accurately, actual resistance and inductance must not change significantly for the interval $0 \leq t \leq t_{B}$.

The above requirements are met using a non-magnetic cylindrical section of stainless steel. The diameter of the bar was chosen to avoid a significant change in impedance caused by skin effect for the spectrum developed by the weld current. The effect of increasing resistance with increasing frequency is known as the skin effect.

Calculations are possible for the resistance and inductance of a conductor with the above geometry. ${ }^{21}$ This approximation is b.asis for the assumption that resistance of this conductor section does not change significantly from the direct current resistance over the range of heats $L^{2}, 2 d$ in the experiment.

Using the reciprocal of the current conduction time as the fundamental irequency, the impedance of the bar was calculated. Based on these calculations, it was determined that increase in resisiance no greater than $0.6 \%$ would be expected at the lowest percent heat relative to the direct current resistance.

The temperature of this bar was monitored during the experiment; and over the entire test period, increase no greater than $10^{\circ} \mathrm{C}$ was noted. Using data from Reference 22 , the temperature increasc was estimated to result in approximately $1 \%$ resistance increase.

Verification of the model involved placing a Type 304 stainless steel bar in the welder and applying constant force while measuring the current through the bar and a voltage drop across a known length of the bar.

Spacing of voltage drop sensing leads was chosen to create resistance approximating that of actual parts, $155 \mu \Omega$. Current within the bar was assumed to be evenly distributed after its transition at the interfaces at the ends. This appears to be a valid assumption based on boundary conditions and the fact that the bar is a reasonably good conductor. ${ }^{23}$
The current signal was measured using a lowinductance pulsed current shunt with impedance characteristics determined prior to testing. The shunt signal and part voltage were amplified using piesision differential amplifiers. These amplifiers were operated at a $-3 \mathrm{~dB}$ bandwidth seting of $100 \mathrm{kHz}$ to avoid introducing frequency response errors into the measurements.

Each amplifier had rated lincarity of $0.01 \%$ of full scale. Output of the signal-conditioning amplificrs was monitored with a digital processing oscilloscope. The voltage and current signals were each sampled at a rate of 100,000 samples per second using the oscilloscope's 16-bit, analog-to-digital converter. Data were collected on the oscilloscope's floppy disk drive. Data were read and analyzed using an IBM PC and a custom written analysis program.

Data were collected for 5, 30, 60, and 90\% heal controller settings for each of three signal wire geometries. Current durations of five cycles were used for each data set. The controller had a constant power characteristic (Figure 2). Signal wire geometries and the welder test configuration are shown in Figure 5. It is assumed that the entire loop area is contained within the opening bounded $I y$ dimensions $\mathrm{W}$ and $\mathrm{H}$ and that there is no inductive contribution by the area within the twisted wires. It was assumed that the loop area was perpendicular to the magnetic flux for each geometry.

\section{DISCUSSION AND RESULTS}

The weld current has four characteristics of interest when comparing the actual and modelled values: peak current value, root mean square value of the current during conduction time, root mean square value of the current for a half cycle, and symmetry of the current waveform. The root mean square value of a current function is the equivalent heating value of the current over a given period if delivered into a resistive load. ${ }^{24}$

The symmetry was of interest for two reasons. First, it was used as an additional criterion to determine whether the model accuraisly describes all aspects of the current function. Second, if the peak current occurred at the midpoint of th: conduction time, this 


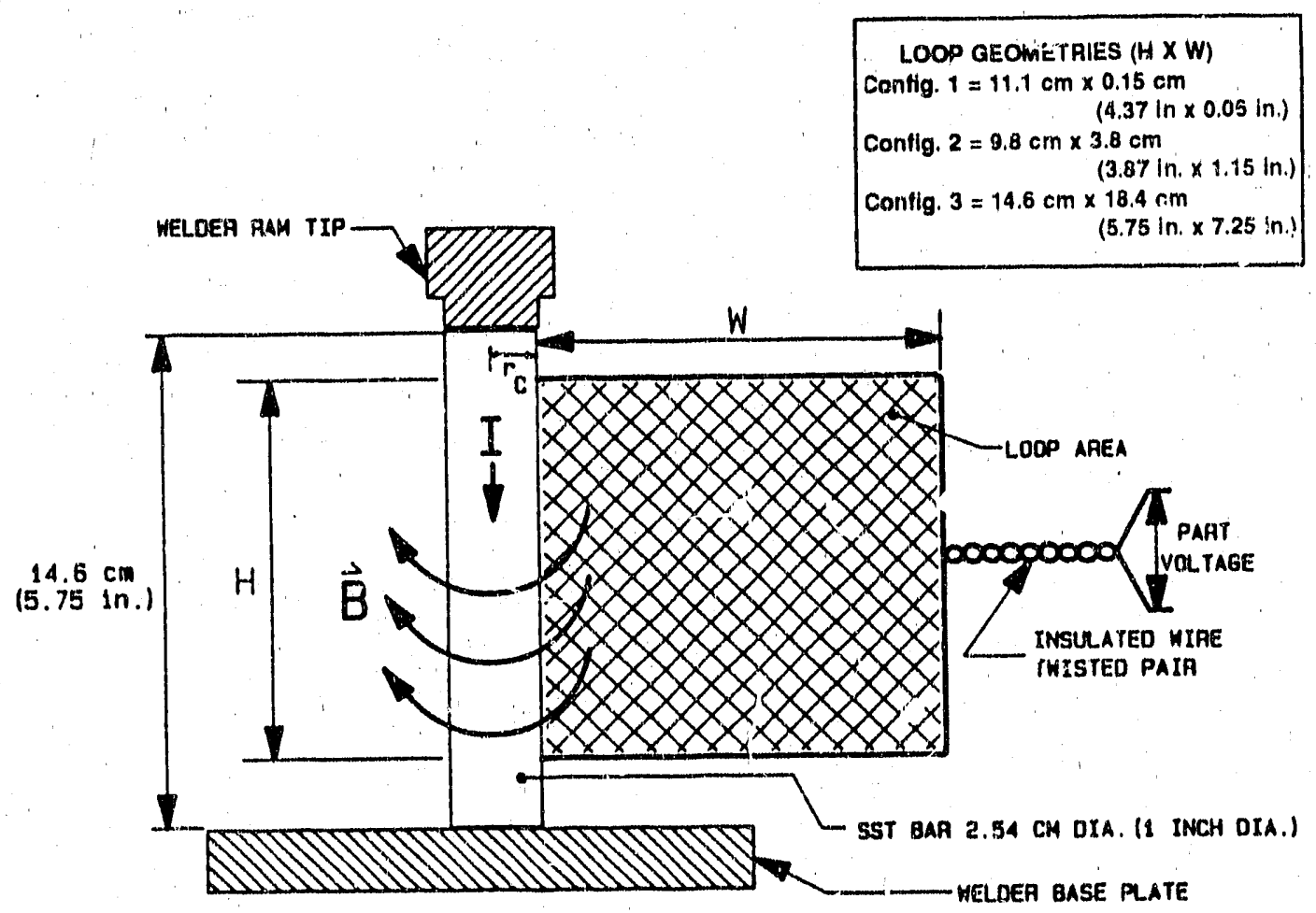

FIGURE 5. Bar Stock and Voltage Signal Wirt Geometries

information could help develop more efficient data analysis algorithms for the data acquisition system and controllers.

Computer programs were written to solve the foregoing equations and analyze the measured data. They compared measured data to model predictions for the experimental conditions.

The equivalent circuit impedance values needed for computer solutions were obtained from a combination of theoretical and measured data. Power system impedance was obtained from power system shortcircuit studies. Feeder impedance was calculated from tabular data presented in Reference 7. Welder "'tertcircuit impedance measurements and calculated values were obtained from the welder manufacturer. This short-circuit impedance includes transformer impedance as well as machine resistance and inductance.

Contact resistances of the ram tip-to-bar and the barto-base plate were estimated from measured values along with estimates from the welder manufacturer.
The contact resistances at the ends of the bar were accounted for in the total weld circuit resistance and were estimated to be $10 \mu \Omega$.

The calculated value of $209 \mu \Omega$ was used in the computer sol itions for the total bulk resistance of the bar. The equivalent part resistance (i.e., resistance of the t" between the voltage-sensiig wire connections) measured by direct current four-wire techniques was 159-163 $\mu \Omega$. Using the bar dimensions and resistivity data, ${ }^{22}$ the bulk resistance was calculated as $158 \mu \Omega$. The computer program solutions used 159 $\mu \Omega$ for the part resistance. The nomina'. unloaded power used in the model solutions was $477 \mathrm{~V}$, the average displayed on the reld controller during testing. Dimension, of the voltage-sersing wire loop areas used in the computer solutions and experimiental testing are given in Figure 5.

Initial estimates of the total secondar $y$ welder impedance, including load impedance, were $358+$ j361 $\mu \Omega$. (The complex impedance is expressed in the rectangular format of $\mathrm{R}+\mathrm{jX}$.) Considerable. uncertainty is associated with these estimates. A total 
impedance of $372+\mathrm{j} 323 \mu \Omega$ yielded the best results for all predictions cited below. This is not an unreasonable discrepiricy. The resistance value difference of these two innpedances is $14 \mu \Omega$, an amount easily accounted for in estimating contact resistances at the bar interfaces and the bulk resistance of the bar.

The welder used for data collection had an additional autotransformer for which little impedance information and no reference literature were available. Because of physical constraints, measurement of its impedance was impossible. This probably accounts for the differences in inductive reactance.

The SCR firing delay angle, $\phi$, in the model computer program was adjusted through an itcrative process until the measured current conduction angle matched the actual measured currents. The program provided necessary data for the comparison noted in Figures 6 through 9. Dimensions of the voltage-sensing loop areas (Figure 5) were used to detcrmine pertinent voltage.

\section{Weld Current}

Current waveforms obtained through the model solution and actual measurements are shown in Figure 6. Note that the conduction angles are matched. The model current waveforms stop at the point of zero current, while the actual current experiences a polarity change and a damped oscillatory decay before current ceases. The root mean square value of the current waveforms during conduction time was calculated over the interval from initiation of current until the actual current crosses zero. Calculation of the half cycle root mean square value of current for the model assumes zero current during the dead time, while the damped oscillatory behavior is included in the mear ared root mean square value. Note that the firing angle delay, $\phi$, is not the same value as the apparent dead time between current pulse ;ince there is conduction past the voltage zero crossing (Figure 4).

Comparison of the root mean square and peak current values is summarized in Figure 7. The root mean

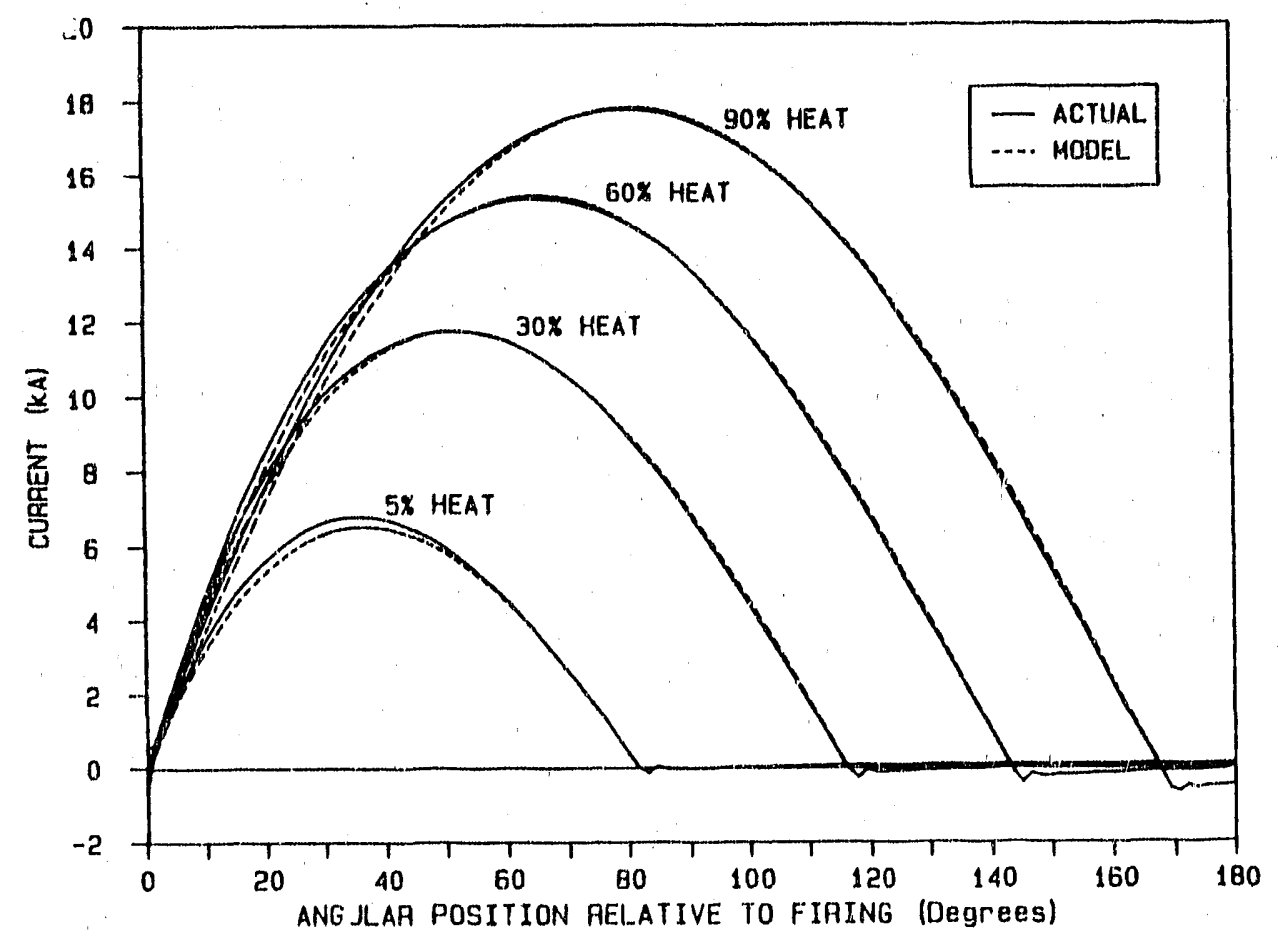

FIGURE 6. Comparison of Model Current to Measured Current 
R.FP-4218

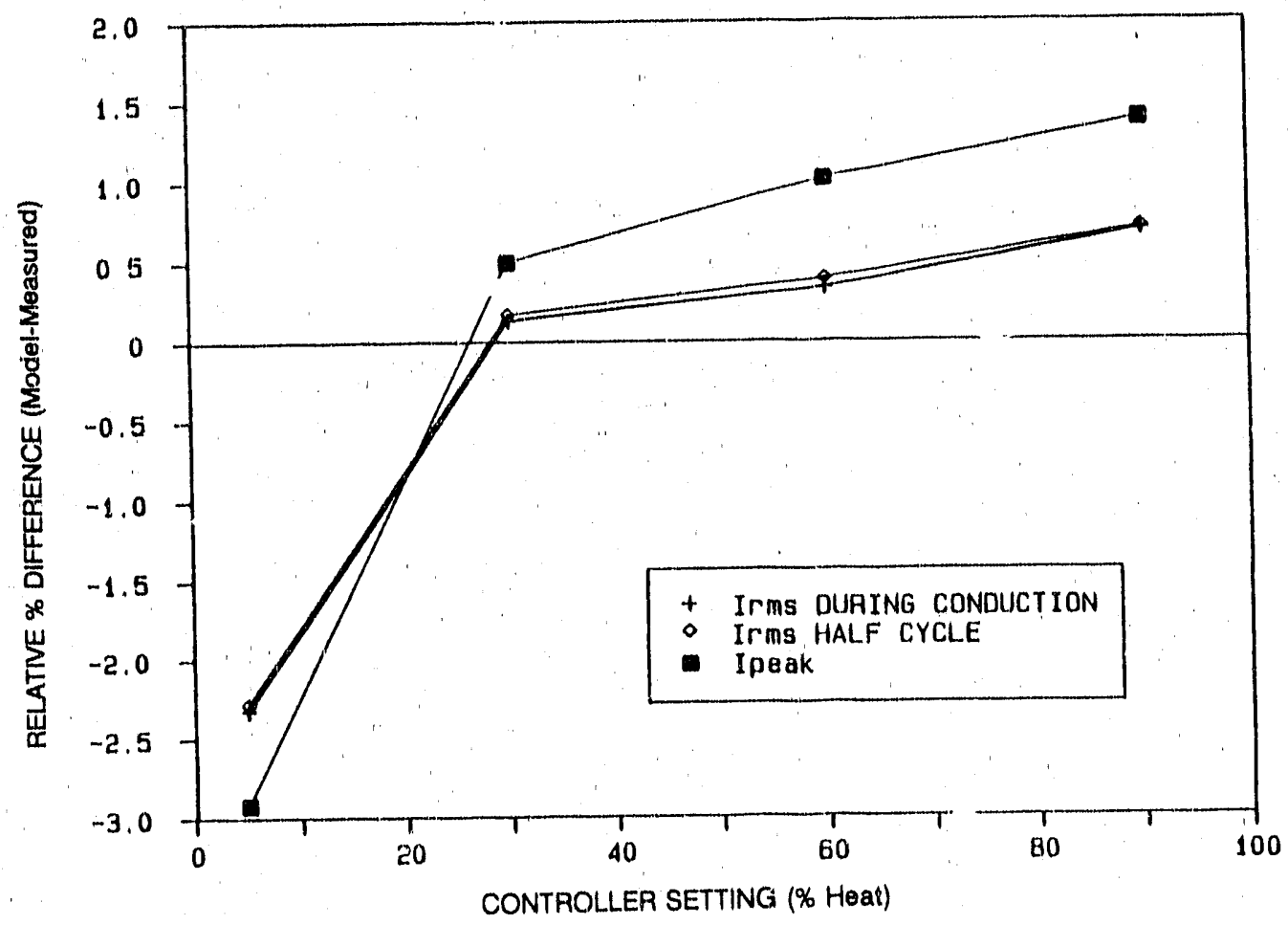

FIGURE 7. Relative Difference Between Measured an' Model Currents

FIGURE 8. Symmetry of Current Peak Relative to Conduction Midpoint

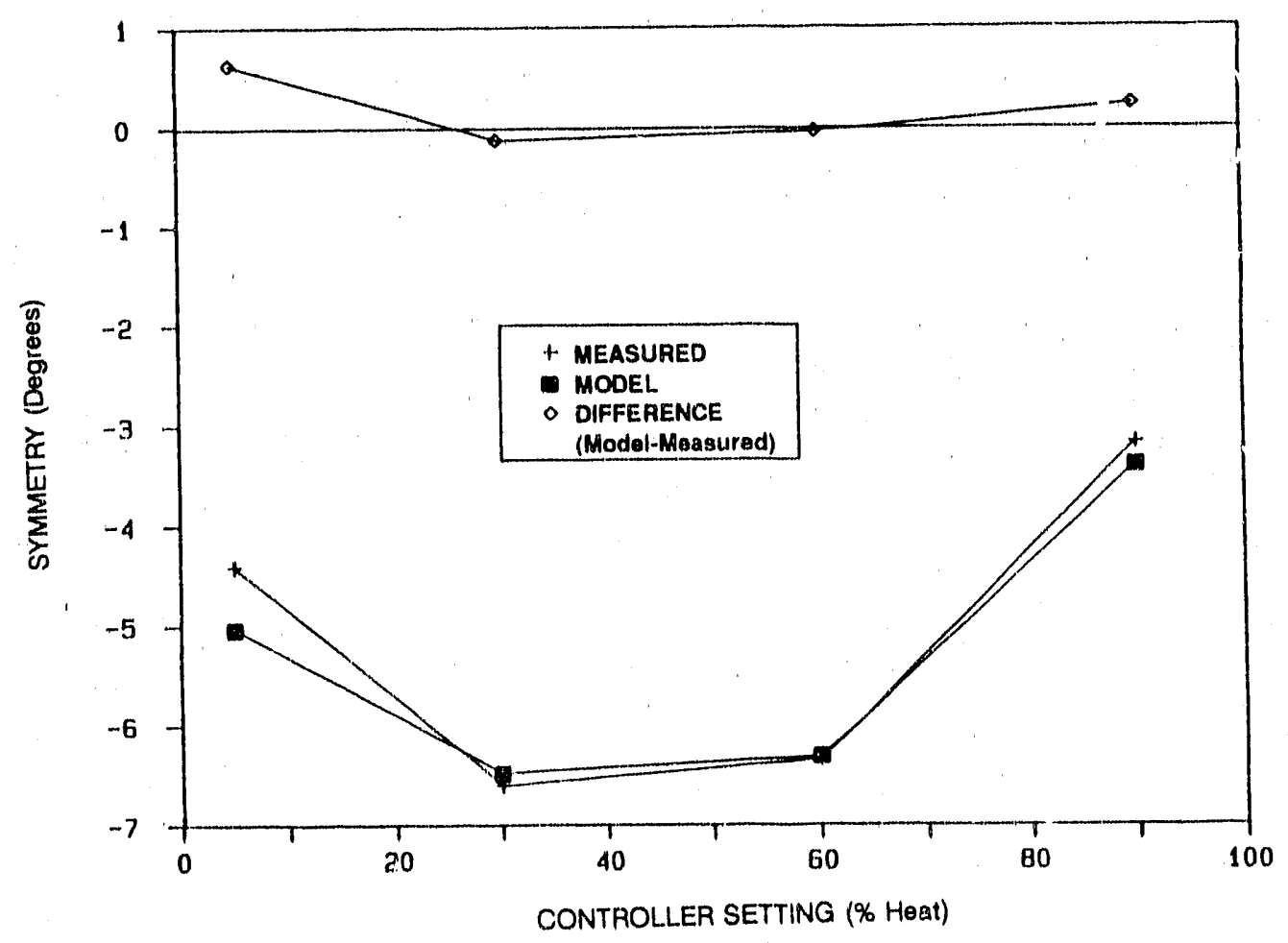




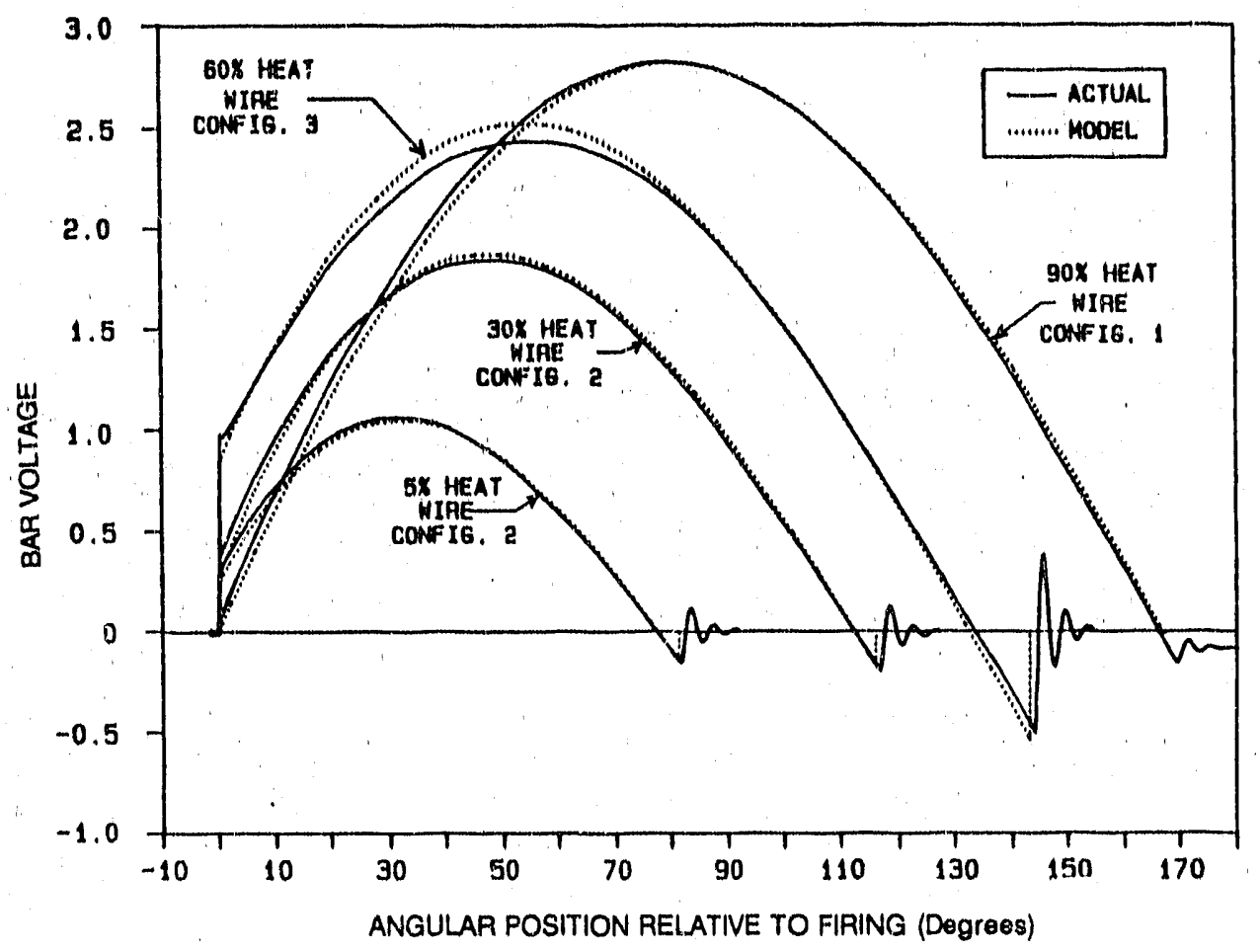

FIGURE 9. Comparison of Model Vcitage to Measured Voltage

square values agree with the model to within $\pm 2.5 \%$ of indicated values. All errors are provided as percent relative errors as found from (model value - measured value) $100 /$ (measured value). The catual current appears higher than the model as the percent heat controller setting is decreased.

In all cases, the measured current slightly leads the model current (Figure 6). This effect is more pronounced at the lower percent heats. The sensor used may be the source of this effect. If the sensor displays a slightly inductive behavior, its output increases as the current pulse frequency component increases. This behavior can be explained, assuming simple models for current shunts. ${ }^{25,26}$ (The inductive behavior of this sensor causes a leading phase shift of its indicated current to the actual current.) Other possible reasons could be the coupling of the magnetic field to the measurement equipment and nonlinear characteristics in the welding transformer. A distance of approximately 1.5 meters was maintained between the measurement equipment and the welder to prevent coupling.

Figure 7 provides relative percent differences in the peak current values obtained. The differences between the model and the actual measured values again follow the same general pattern as the root mean square values, the agreement being within approximately $\pm 1.5 \%$ until encountering shorter duration current pulses near $5 \%$ heat. The peak current values at $5 \%$ heat disagree by nearly $3 \%$.

Figure 8 provides data on symmetry of the current waveform. Because of the exponential term in Equation 3 , the current function is not purely sinusoidal. The symmetry value is defined as the time or angular difference between midpoint of the current and the time or angle at the actual current peak (Figure 4). Therefore, a negative value of symmetry indicates that the current peak is encountered prior to the waveform midpoint.

The actual and measured values of symmetry for the experimental heat settings are provided in Figure 8. Differences between actual and model values of symmetry (model errors) are also provided. The maximum difference between the model and the measured value is less than one degree. This corresponds to $46 \mu \mathrm{s}$ at $60 \mathrm{~Hz}$, or approximately four data samples obtained from the sampling oscilloscope. There are approximately \pm 2 data samples of 
RFP-4218

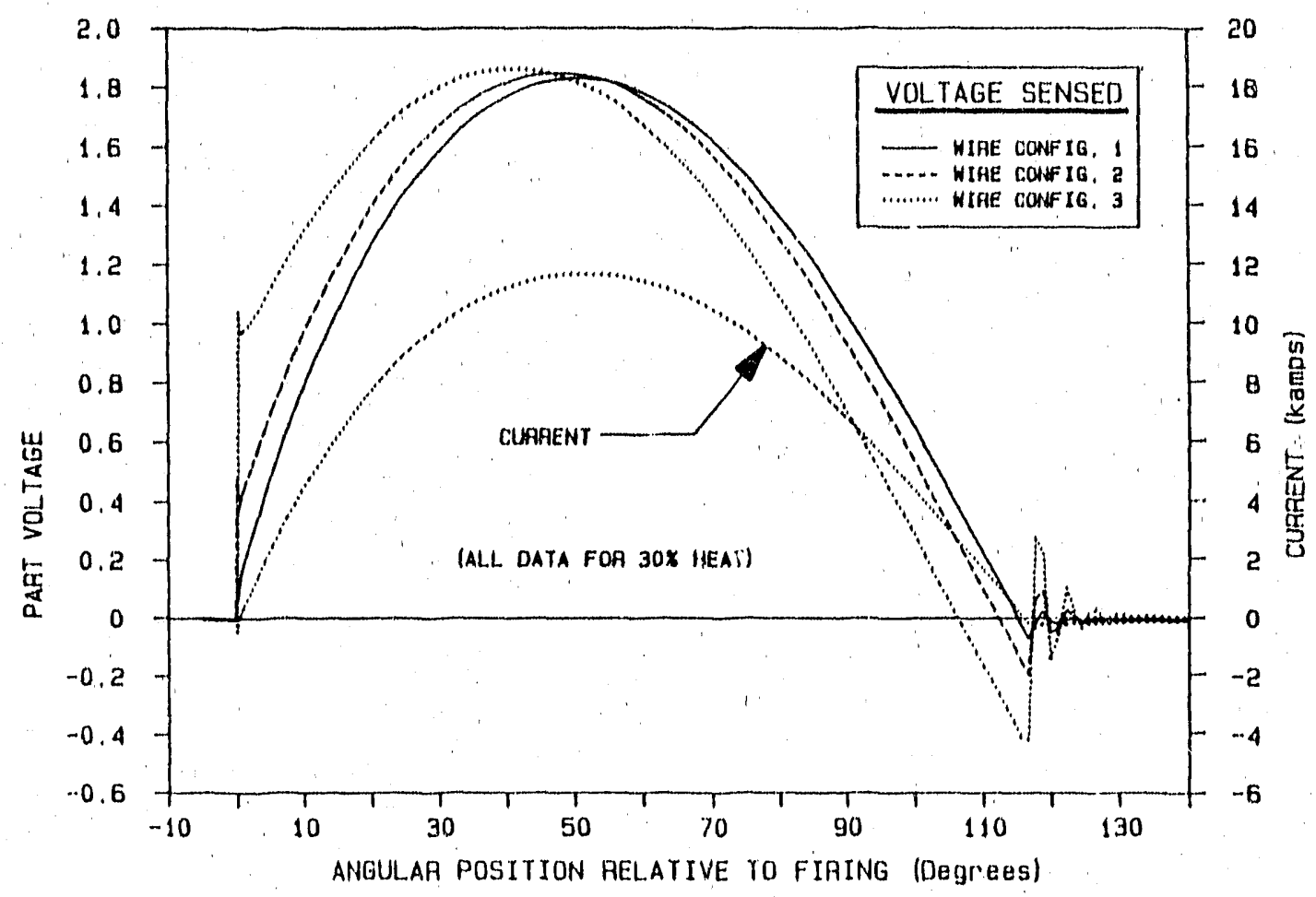

FIGURE 10. Effects of Increased Voltage Sense Wire Loop Area

uncertainty in determining when the current peak occurs. This is from finite digitizing of the current waveform. Based on the above digitizing errors, agreement of the symmetry is considered well within the measurement uncertainty.

Agreement between the model and actual measured values is considered excellent for all criteria previously cited. Discrepancy to $\pm 3 \%$ for the various current magnitudes is well within the uncertainty of the best measurement equipment and techniques available. ${ }^{27}$ Except for the current sensor, equipment used for this experiment is the same as that used for calibration. The agrement of the symmetry values is also excellent, considering there are approximately two data samples of ambiguity in determining when peak current occurs.

\section{Part Voltage}

The primary use of the part voltage signal is to determine part resistance, power, and energy. Atlachment of voltage-sensing wires to weldments significantly limits the use of part voltage and resultant part resistance values in a production environment. In many such cases, physical limitations for attaching voltage-sensing wires can result in large loop areas and associated large induced crror voltages. Variations in the induced voltage as the loop area changes from setup to sctup can also cause significant differences in the measured part resistance. Effects of increasing the voltage-sensing wire loop area for a given current pulse are depicted in Figure 10. Note that as the loop area increases, the initial voltage step increases at current initiation and also increases in a negative direction at the current extinction. Slope of the voltage at the current peak also increases as the loop area increases.

The typical method of determining part resistance has its basis in Equation 10. The slope of the current function, or di/dt, is zero at the current peak. Since the di/dt term is zero at this instant, the induced voltage must also be zero. Therefore, if the part voltage is divided by the weld current at the instant $\mathrm{di} / \mathrm{dt}=0$, the true part resistance should be availatile without induced error voltages affecting the measured value. This method, however, is susceptible to timing crrors between the current and voltage waveforms. The resistance crror increases for a given amount of time 
misalignment as the loop area increases because of increasing slope in the voltage waveform.

In some production operations, it may be impossible to eliminate or minimize the voltage sense loop area because of fixturing and physical constraints. Although extensive analysis is incomplete, it is possible to introduce a $3 \%$ relative error in the measured value of resistance by a $100-\mu$ s delay of the current waveform with Configuration 3 (Figure 5). This time delay equates to two degrees ( 35 milliradians) of phase shift at $60 \mathrm{~Hz}$. This amount of phase shift is easily obtained through mismatched characteristics in current and voltage signal conditioning circuits and current sensors.

Figure 9 provides a comparison of the nodelled and actual part voltage waveforms for several luon areas and controller settings. Although the various geometries of voltage-sensing wires were measured when the experiment was conducted, the exact loop area dimensions were not precisely controlled. Dimensions of the loop are approximate and probably had an uncertainty of $\pm 3 \mathrm{~mm}$. Perpendicularity of the loop area to the current path was not precisely controlled or measured during the experimental process.

Also, it was impossible to have right-angle bends in the signal wires as the theory assumes. The theory on which the loop area inductance calculations were based assumes an isolated, infinitely long conductor. This is certainly not the case in the geometry shown in Figure 5 since the current in the ram may approach this necessary condition. However, the current path is at right angles to the bar as it exits the bar into the base plate.

Agreement of the predicted voltage waveforms to the measured data indicate acceptable agreement when geometric considerations are taken into account. The model accurately predicts the initial voltage step at the beginning of the waveform. The model also predicts amplitude of the voltage at the time of turnoff.

It should be noted that the model assumes a constant resistance. In practice, the weld joint resistance changes during the welding process. The model can be utilized in a piece-wise continuous fashion and remain accurate if the change in resistance occurs over longer intervals than one-half cycle. If however, the resistance changes during the course of a half cycle current pulse, the model will not be valid.

High-speed photography of an actual weld shows that the part joint responds to each current half cycle at the teginning of the welding preheat process. ${ }^{5}$ Apparently, this response rate does not continue once the part deformation slows and the initial interface breakdown occurs.

There may be a significant mcasurement problem in determining whether the part resistance changes significantly in less than one-half cycle since there is only one occurrence of $\mathrm{di} / \mathrm{dt}=0$ where the part voltage can be measured without induced voltage errors. It may be possible to measure the part dynamic resistance in less than half-cycle increments if corrections for the inductance, either physical or numerical, can be made. ${ }^{28}$

\section{CONCLUSIONS}

The simple linear constant coefficient differential equation predicts the critical parameters of symmetry to within one degree and predicts peak and root mean square current values to within $\pm 3 \%$ of the measured values. This is well within the estimated experimental uncerainty of $\pm 3.5 \%$. The part voltage equation appears to predict accurately the general shape of the measured waveform. The limitations, narncly the resistances, must be constant for at least one-half cycle. Increased insight into interaction of the critical variables should be possible using the simple model outlined.

Based on extrapolations and extensions of this model, faster control and data acquisition system algorithms appear possible. This includes determination of dynamic nart resistance in less than a half cycle using approximations and assumptions gained from the model. The finite element motelling activities should also benefit from this model since the actual current time functions can be used, rather than a constant equivalent current.

Future work will include investigation of signal conditioning amplifier errors on measurement if part resistance and other critical parameters of each 
waveform. The resistance time rate of change will be investigated to determine whether significant resistance changes take place in less than a half cycle. Rapid changes in actual part resistances would determine validity of the linear constant coefficient model as applied to actual welds. Also, investigation is needed to determine the error in part resistance resulting from time misalignment of part voltage and current signals.

\section{REFERENCES}

1. R. Holm, Electric Contacts-Theory and Application, 4th ed., p 10, Springer-Verlag, New York, NY, 1967 .

2. H. Udin, E. R. Funk, and J. Wulff, Welding for Engineers, pp 44-45, John Wiley \& Sons, New York, NY. 1954.

3. H. Udin et al., op. cit., pp 62-67.

4. S. A. Gedeon et al., "Measurement of Dynamic Electrical and Mechanical Propertics of Resistance Spot Welds," American Weiding Society Journal , pp 381-384, December 1987.

5. D. R Andrews and J. Broomhead, "Quality Assurance for Resistance Spot Welding," Welding Journal, pp 432-433, June 1975.

6. J. R. Eaton, Electric Power Transmission Systems, p 65, Prentice-Hall, Inc., Englewood Clif's, NJ, 1972.

7. Resistance Welding Data Book-Theory and Practice, 4th ed., pp 120-127, P. R. Mallory \& Co., Inc., Indianapolis, IN, 1951.

8. S. A. Nasar, Theory and Problems of Electric Machines and Electromechanics, pp 22-25, McGraw-Hill Bonk Co., Naw York, NY, 1981.

9. R. Holm, op. cit., pp 9-42.

10. R. Holm, op. cit., p 54.

11. C. T. A. Johnk, Electromagnetic Fields and Waves, pp 521-529, John Wiloy \& Sons, Now York, NY, 1975.
12. R. Holm, op. cit., pp 27-29, 37-42.

13. H. Udin et al., op. cit., pp 44-51.

14. Resistance Welding Data Book, op. cit., pp 105106.

15. D. R. Graharn and J. C. Hey (Ed.), SCR Manual, 5th ed., pp 12-37, General Electric Corp., Auburn, NY, 1977.

16. J. A. Edminister, Theory and Problems of Electric Circuits, pp 249-250, McGraw-Hill Book Co., New York, NY, 1965.

17. S. A. Gedeon et al., op. cit., pp 379-381.

18. T. R. Bieler, J. R. Soingarn, and W. E. Jorgenson, Voltage Drop and Temperature Measurements During Tube Closure by Resistance Welding, pp 13-14, SAND 82-8024, Sandia National Laboratory, July 1982.

19. C. T. A. Johnk, op, cit., p 290.

20. Andrews and Broomhead, op, cit., pp 382-384.

21. C. T. A. Johnk, op, cit., pp 527-529.

22. T. K. Chu and C. Y. Ho, "Thermal Conductivity and Electrical AISI Stainless Steels," Thermal Conductivity, p 88, Plenum Press, Now York, NY, 1978.

23. C. T. A. Johnk, op. cit., pp 143-150.

24. E. Frank, Electrical Measurement Analysis, p 18, McGraw-Hill Book Co., New York, NY, 1959.

25. D. E. Destefan, " 1000 Ampere AC/DC Current Source for the Calibration of Welding Systems," IEEE IM/TC-86 Conference Proceedings, pp 8487, Boulder, CO, March 25-27, 1986.

26. W. F. Praeg, "Low-Inductance Shunts for Mcasuring Large Pulsed Currents," pp 204-205, NBS' Special Pub. No. 628, National Bureau of Standards, Boulder, CO.

27. S. B. Booker, Private comm., Sandia National Laboratory, Albuquerque, NM., February 1987.

28. S. A. Gedeon et al, op, cit., pp 382-383. 

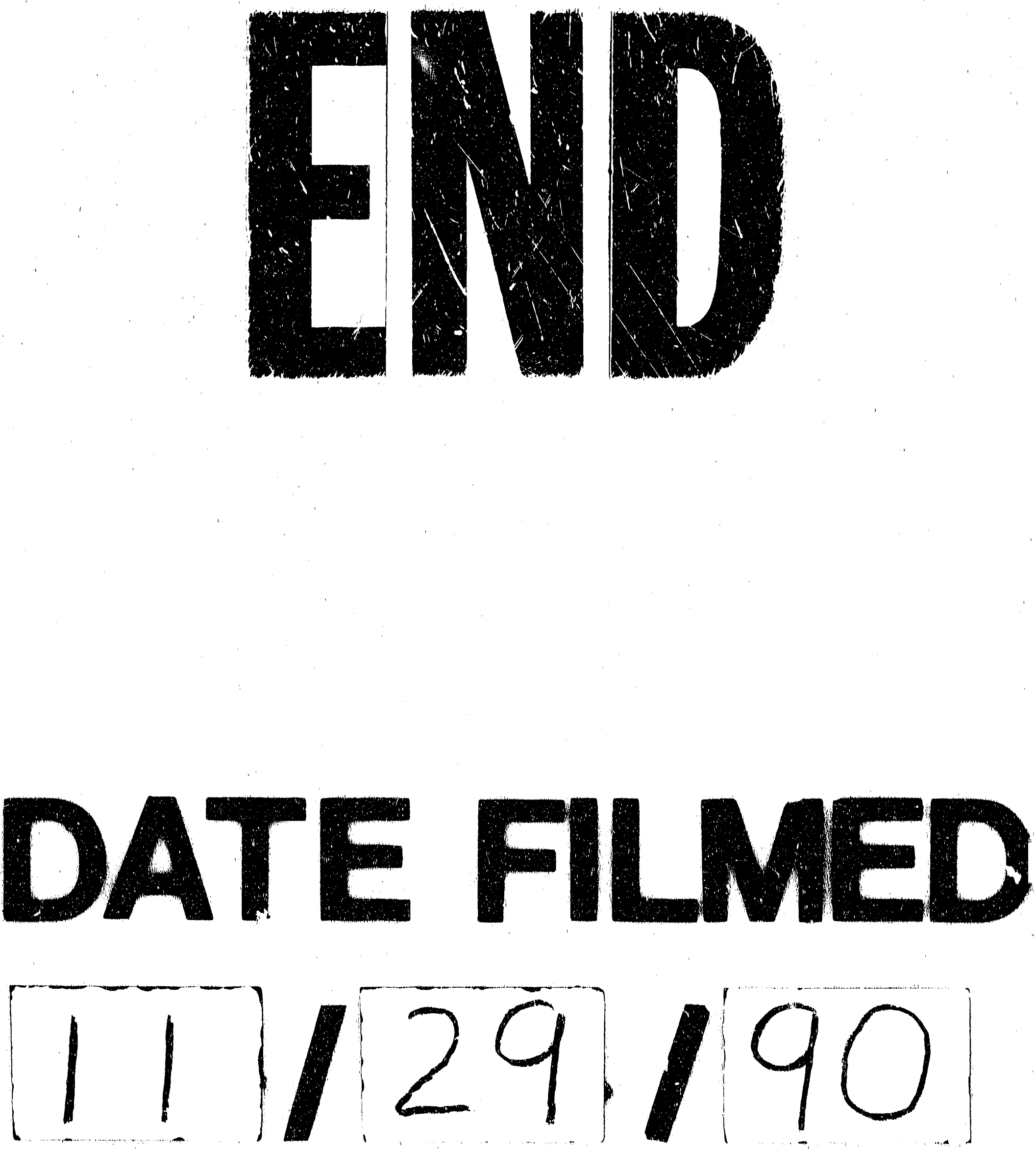
